Article

\title{
Construction of an Onion (Allium cepa L.) Genetic Linkage Map Using Genotyping-by-Sequencing Analysis with a Reference Gene Set and Identification of QTLs Controlling Anthocyanin Synthesis and Content
}

\author{
Yousoo Choi ${ }^{1,2}$, Sunggil Kim ${ }^{3}$ and Jundae Lee ${ }^{1, *(D)}$ \\ 1 Department of Horticulture, Institute of Agricultural Science \& Technology, Jeonbuk National University, \\ Jeonju 54896, Korea; youso1127@naver.com \\ 2 National Agrobiodiversity Center, National Institute of Agricultural Sciences, Rural Development \\ Administration, Jeonju 54874, Korea \\ 3 Department of Plant Biotechnology, Biotechnology Research Institute, Chonnam National University, \\ Gwangju 61186, Korea; dronion@jnu.ac.kr \\ * Correspondence: ajfall@jbnu.ac.kr
}

Received: 24 April 2020; Accepted: 11 May 2020; Published: 12 May 2020

\begin{abstract}
Anthocyanins, the pigmented flavonoids responsible for red and blue colors in horticultural products, promote human health by preventing cancers and lowering the risk of cardiovascular disease. Red onions contain several cyanidin- and peonidin-based anthocyanins. In this study, we constructed a single-nucleotide polymorphism (SNP)-based genetic linkage map in an $\mathrm{F}_{2}$ segregating population derived from a cross between the inbred line 'SP3B' (yellow bulb) and the doubled haploid line ' $\mathrm{H6}$ ' (red bulb) to identify quantitative trait loci (QTLs) for total anthocyanin content of onion bulbs using a genotyping-by-sequencing (GBS) analysis based on a reference gene set. A total of $101.9 \mathrm{Gbp}$ of raw sequences were generated using an Illumina HiSeq 2500 system and a total of 1625 SNP loci were identified with the criteria of three minimum depths, lower than 30\% missing rate, and more than $5 \%$ minor allele frequency. As a result, an onion genetic linkage map consisting of 319 GBS-based SNP loci and 34 high-resolution melting (HRM) markers was constructed with eight linkage groups and a total genetic distance of $881.4 \mathrm{cM}$. In addition, the linkage groups were assigned to corresponding chromosomes by comparison with the reference genetic map OH1×5225 through marker development based on common transcripts. The analysis revealed one major QTL, $q A S 7.1$, for anthocyanin synthesis and two significant QTLs, $q A C 4.1$ and $q A C 4.2$, for anthocyanin content. The QTL $q A S 7.1$, located on chromosome 7 with a phenotypic variation of $87.61 \%$, may be a dihydroflavonol 4-reductase (DFR) gene that determines whether the bulb color is red or yellow. The QTLs $q A C 4.1$ and $q A C 4.2$ are separately positioned on chromosome 4 with $R^{2}$ values of $19.43 \%$ and $26.28 \%$, respectively. This map and QTL information will contribute to marker development and breeding for high anthocyanin content in bulb onion.
\end{abstract}

Keywords: anthocyanin; bulb color; GBS; HRM; QTL; transcriptome

\section{Introduction}

Bulb onion (Allium cepa $\mathrm{L}$; $2 \mathrm{n}=2 \mathrm{x}=16$ ) is an economically and nutritionally important vegetable crop worldwide [1]. The health benefits of onion are due to several functional compounds, including anthocyanins (mainly in red/purple onions), flavanols such as quercetin (mainly in yellow/brown onions), and alk(en)yl cysteine sulphoxides (ACSOs) [2]. Anthocyanins, type of 
flavonoid, are water-soluble vacuolar pigments that confer red, blue, and purple colors in horticultural products depending on the $\mathrm{pH}$ [3]. Red onions contain four major cyanidin-based anthocyanins; cyanidin 3-glucoside (Cy 3-Glc), cyanidin 3-laminaribioside (Cy 3-Lam), cyanidin 3-malonylglucoside (Cy 3-MaGlc), and cyanidin 3-malonyllaminaribioside (Cy 3-MaLam) [4], and two minor peonidin derivatives, peonidin 3-glucoside and peonidin 3-malonylglucoside [5].

Inheritance of onion bulb colors appears in a complex pattern [6,7]. Previous inheritance studies have reported the presence of six major loci $(I, C, G, L, L 2$, and $R$ ) that are responsible for bulb colors [1]. Particularly, the $R$ locus and either the $L$ or $L 2$ locus are complementarily involved in the control of yellow and red bulb colors $[7,8]$, and the $R$ and $L$ loci were reported to correspond to the dihydroflavonol 4-reductase (DFR) and anthocyanidin synthase (ANS) genes, respectively [8]. The DFR and ANS genes were assigned to chromosomes 7 and 4, respectively; using two complete sets of shallot $(A$. cepa) alien monosomic addition lines [9]. Transcripts of the DFR gene were seen in red onions but were absent in yellow onions [10], and it was suggested that blockage of DFR transcription or translation results in a lack of anthocyanin production in yellow onion [11]. A total of $16 D F R-A$ alleles were identified, and the process for identification of the alleles was reported [12-14]. On the other hand, ANS was related to a pink color as well as anthocyanin production in onion [15-18]. However, the genetic inheritance of anthocyanin content in red onion is poorly understood.

Genomic and genetic studies of onion are difficult due to its huge genome size (16.3 Gbp), biennial life cycle, cross-pollinating nature, and high inbreeding depression [1]. For these reasons, the whole genome sequencing of the onion is not yet completed [19]. Despite the difficulties, several studies on genetic linkage mapping and marker development in the onion have been made. A low-density genetic map of the onion, including 14 random amplified polymorphic DNA (RAPD) and 110 restriction fragment length polymorphism (RFLP) markers, was first constructed using $58 \mathrm{~F}_{3}$ families derived from a single $F_{1}$ plant from the cross of 'Brigham Yellow Globe 15-23' (BYG15-23) and 'Alisa Craig 43' (AC43) [20]. An interspecific genetic map of A. roylei $\times$ A. cepa was made using 692 amplified fragment length polymorphism (AFLP) markers [21]. In addition, the linkage groups were assigned to the chromosomes of $A$. cepa L. via monosomic addition lines [22]. A total of 13 markers, including two cleaved amplified polymorphic sequence (CAPS) and 11 single-strand conformation polymorphism (SSCP) markers, were developed from 128 expressed sequence tag (EST) sequences and positioned on the 'BYG15-23' $\times$ 'AC43' map [23]. In the same population, 100 new genetic markers were developed from EST sequences and the 'BYG15-23' $\times$ 'AC43' map consisting of 14 linkage groups encompassing $1907 \mathrm{cM}$ was constructed [24]. A total of 37 simple sequence repeat (SSR) markers were developed to distinguish between 35 onion cultivars [25], and 56 EST-SSR and four genomic SSR markers were used for genetic diversity analysis of 89 inbred and open-pollinated bulb onions [26].

Next-generation sequencing (NGS) technologies have made it easier to identify a large number of single-nucleotide polymorphisms (SNPs) to develop SNP markers and to construct genetic linkage maps for plant genetics and breeding [27]. A total of 205 markers, including 11 indel, 90 CAPS, and 104 high-resolution melting (HRM) markers, have been developed from NGS data, and a framework linkage map of over $800 \mathrm{cM}$ spanning all chromosomes was constructed in an $\mathrm{F}_{2}$ population from a cross between the two bulb onions 'Nasik Red' and 'CUDH2150' [28]. The 20 robust single copy SSR markers selected from 166 SSRs were used for the estimation of genetic diversity within and among 24 bulb onion populations [29]. A total of 597 SNPs identified from cDNA libraries between the bulb onions 'OH1' and ' $5225^{\prime}$ were positioned on a genetic map consisting of ten linkage groups, and the map was compared with the 'BYG1523' × 'AC43' map using 223 common SNPs [30]. A total of 54,165 protein-coding genes among 165,179 assembled transcripts totaling $203 \mathrm{Mb}$ were generated with de novo high-throughput RNA sequencing (RNA-Seq) analysis [31]. In addition, 35,505 isoforms, designated as draft reference transcripts (DRTs, version 1.0), were produced using long-read sequencing [32]. The 301 SNP markers based on kompetitive allele specific PCR (KASP) assays were developed using transcriptome sequencing, and two interspecific genetic maps between $A$. roylei and $A$. fistulosum and between $A$. cepa and A. roylei were constructed using the SNP markers [33]. 
From genotyping-by-sequencing (GBS), 175 SNPs and 57 from Fluidigm SNP assays were used for the construction of an onion genetic map, which consisted of eight linkage groups and covered a total length of $1339.5 \mathrm{cM}$ [34]. A total of 1904 SNPs were discovered in 192 Korean short-day onion inbred lines using double digest restriction site-associated DNA sequencing (ddRAD-seq) [35].

In this study, we aimed to construct an onion genetic linkage map using GBS analysis with the previously reported reference gene set and without the reference whole-genome sequence and to identify quantitative trait loci (QTLs) controlling anthocyanin synthesis and content in an $\mathrm{F}_{2}$ population.

\section{Results}

\subsection{SNP Detection and Genotyping Using GBS Analysis}

GBS analysis was carried out with $96 \mathrm{~F}_{2}$ onion plants for SNP detection and genotype identification. In total, one billion raw reads and $101.9 \mathrm{Gbp}$ of sequences were obtained using Illumina HiSeq 2500 paired-end sequencing (Table 1). The raw reads were classified into 96 groups (samples) using the barcode sequences. The average number of reads in each group was $10,075,947$. Subsequently, the demultiplexed reads were trimmed by eliminating barcodes, adaptors, and low-quality sequences. The average length of trimmed reads per sample was $77.75 \mathrm{bp}$, and accounts for $86.2 \%$ of the total raw reads (Table 1 ). The trimmed reads were mapped on the reference gene set of bulb onion (Table 2) [31]. As a result, only 35.5\% of the raw reads were mapped and the total number of mapped reads was 358,301,156 (Table 1). The average number of each mapped region was 16,718 , and the average depth of each mapped region was 81.42 (Table 1). The average length of the mapped regions was 1,855,555 bp, which covered $0.9141 \%$ of the onion reference gene set (Table 1 ). Finally, a SNP matrix consisting of 96 samples and 8431 SNPs was generated (Table 1). After filtering with a minimum depth of three, less than $30 \%$ missing rate, and over $5 \%$ major allele frequency, 1625 SNPs were obtained (Table 1 and Table S1).

Table 1. Summary of genotyping-by-sequencing data generated by using transcriptome sequences as a reference.

\begin{tabular}{cc}
\hline Summary of Illumina Sequencing & Data \\
\hline Number of plants for multiplexing & 96 \\
Total number of raw reads generated & $1,008,750,538(100 \%)$ \\
Total base number of raw reads $(\mathrm{bp})$ & $101,883,804,338(101.9 \mathrm{Gbp})$ \\
Total number of demultiplexed reads & $967,290,922(95.9 \%)$ \\
Total number of trimmed reads & $869,413,090(86.2 \%)$ \\
Total number of mapped reads & $358,301,156(35.5 \%)$ \\
Total number of mapped regions & $1,604,901$ \\
Average depth of mapped region & 81.42 \\
Total length of mapped regions $(\mathrm{bp})$ & $1,855,555(1.9 \mathrm{Mbp})$ \\
Total length of the reference gene set $(\mathrm{bp})$ & $202,991,716(203.0 \mathrm{Mbp})$ \\
Coverage of the reference gene set & $0.9141 \%$ \\
Total number of SNPs detected & 8431 \\
Total number of SNPs filtered & 1625 \\
\hline
\end{tabular}

Table 2. Summary of transcript-assembled contigs used as an onion reference reported by Kim et al. [31].

\begin{tabular}{cccccc}
\hline $\begin{array}{c}\text { Number of } \\
\text { Assembled Contigs }\end{array}$ & $\begin{array}{c}\text { Total Length } \\
\mathbf{( b p )}\end{array}$ & $\begin{array}{c}\text { Minimum } \\
\text { Length (bp) }\end{array}$ & $\begin{array}{c}\text { Maximum } \\
\text { Length (bp) }\end{array}$ & $\begin{array}{c}\text { Average } \\
\text { Length (bp) }\end{array}$ & $\begin{array}{c}\mathbf{N}_{\mathbf{5 0}} \\
\text { Length (bp) }\end{array}$ \\
\hline 165,179 & $202,991,716$ & 200 & 16,504 & 1228 & 1756 \\
\hline
\end{tabular}




\subsection{Development of HRM Markers for Comparative Mapping}

A total of 248 primer sets for HRM markers were designed based on common SNPs between the populations $\mathrm{SP} 3 \mathrm{~B} \times \mathrm{H} 6$ (in this study) and $\mathrm{OH} 1 \times 5225$ [30]. Among them, only 34 were polymorphic (Figure 1). The HRM marker types were clearly separated into three groups: A (SP3B genotype), B (H6 genotype), and H (heterozygous genotype; Figure 1). The markers were positioned widely throughout the genome on chromosomes 1-8. Detailed marker information is listed in Table 3.

(1) i34152_369-H

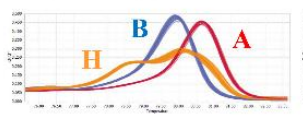

(6) i332865_1404-II

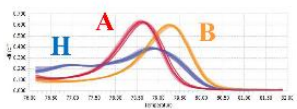

(11) i39498_201-H

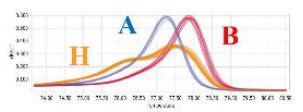

(16) i26442_1225-H

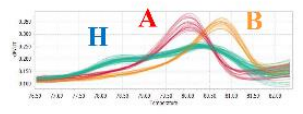

(21) i29728_1131-H

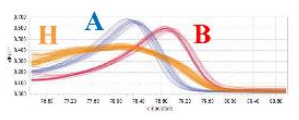

(26) i35768 1013-H

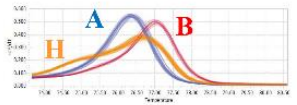

(31) i28923_2628-H

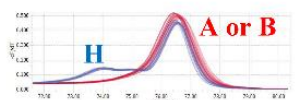

(2) i37206_320-H

H

(7) i332416_685-II

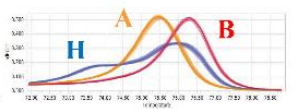

(12) i33531_1155-H

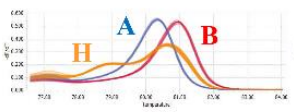

(17) i26526_748-H

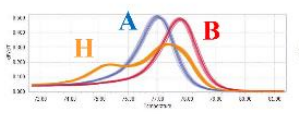

(22) i30593_868-H

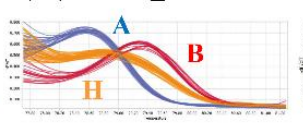

(27) i32739_152-H

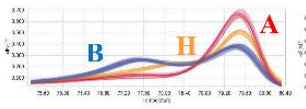

(32) i31126 1315-H

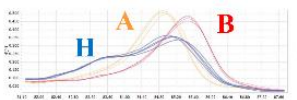

(3) $\mathrm{i} 26238 \_573-\mathrm{H}$

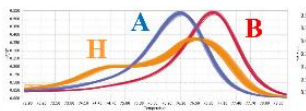

(8) i33538_1298-H

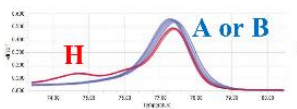

(13) i35038_601-H

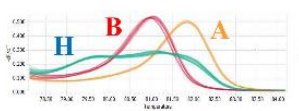

(18) i32123 1465-H

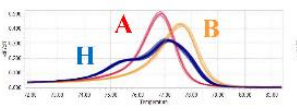

(23) i36364_683-H

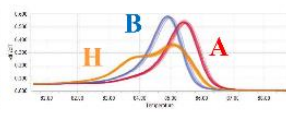

(28) i36782_698-H

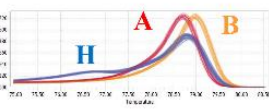

(33) i30907_420-H

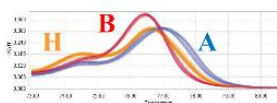

(4) i26198_779-H

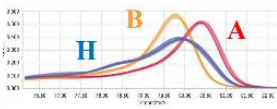

(9) i26131_2020-H

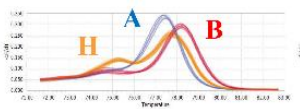

(14) i26005_1583-H

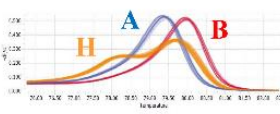

(15) i29163_2080-H

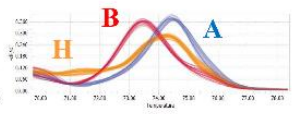

(19) i25881_1343-2-H (20) i25881_1343-1-H

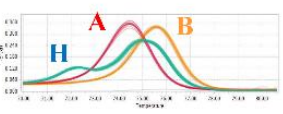

(24) i29592_700-H

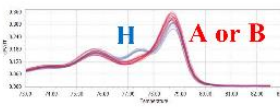

(29) $139918 \_357-\mathrm{H}$

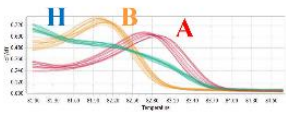

(25) i30880_1388-H

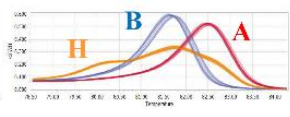

(30) i29101_1894-H

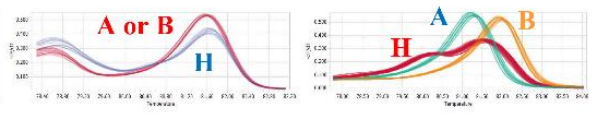

(34) i31261_1350-H

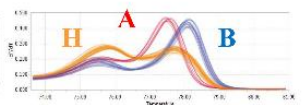

Figure 1. Melting curves of 34 high-resolution melting (HRM) markers developed in this study. A, marker type of female parent (SP3B); B, marker type of male parent (H6); H, marker type of heterozygote. 
Table 3. List of HRM markers developed in this study.

\begin{tabular}{|c|c|c|c|c|c|c|c|c|c|c|}
\hline \multirow[b]{2}{*}{ No. } & \multicolumn{7}{|c|}{ SP3B $\times$ H6 Map } & \multicolumn{2}{|c|}{ OH1 $\times 5225$ Map $^{\text {Z }}$} & \multirow{2}{*}{$\begin{array}{c}\text { Transcript ID }^{y} \\
\text { AC.Combine.Assembly.v.1. }\end{array}$} \\
\hline & Chr. No. ${ }^{x}$ & $\begin{array}{l}\text { Position } \\
\text { (cM) }\end{array}$ & Marker Name & Forward Primer & Reverse Primer & H6 & SP3B & Chr. No. ${ }^{x}$ & $\begin{array}{l}\text { Position } \\
\text { (cM) }\end{array}$ & \\
\hline 1 & 1 & 23.1 & i34152_369-HRM & $\begin{array}{l}\text { TCCACATATCTCATATTGCGCTCA } \\
\end{array}$ & \begin{tabular}{|l|l} 
CTTTGGCTTAACTTACCCGATTAC \\
\end{tabular} & G & A & 1 & 8.7 & AC.Combine.Locus_5700 \\
\hline 2 & 1 & 63.6 & i37206_320-HRM & CCGGTTGTGGTTGGTCGAA & ACAAGTTAGTGGCACGTTACAAAA & G & $\mathrm{T}$ & 1 & 59.0 & AC.Combine.Locus_9298 \\
\hline 3 & 2 & 39.6 & i26238_573-HRM & ACAAACCTTATGCAGATACACTCA & GCAACATCAAAAGCTCCCCATC & $\mathrm{T}$ & $\mathrm{C}$ & 2 & 67.3 & AC.Combine.Locus_14118 \\
\hline 4 & 2 & 55.4 & i26198_779-HRM & TTCTATTACCGGAGCTGTAGTTGG & CAAATGCAATATCTCCAAGGGCTT & G & A & 2 & 95.5 & AC.Combine.Locus_9799 \\
\hline 5 & 2 & 82.8 & i30225_1161-HRM & GAAGGGACAGTTCAAGGTAGTAGG & TCTCAAATTCCTTCTCCAACTTCA & G & A & 2 & 154.5 & AC.Combine.Locus_7495 \\
\hline 6 & 2 & 96.9 & i32865_1404-HRM & TAGTCAGAATCTTCCTCTCCTGGT & AGTGGAGGAAGATGAAGAAGTTGA & A & $\mathrm{G}$ & 2 & 193.2 & AC.Combine.Locus_19254 \\
\hline 7 & 2 & 100.7 & i32416_685-HRM & AGCAATGAAGTACGATTTACAGCA & TGAAGAAGAACCCTCCAACGTTAT & $\mathrm{T}$ & $\mathrm{C}$ & 2 & 203.3 & AC.Combine.Locus_17664 \\
\hline 8 & 2 & 116.5 & i33538_1298-HRM & AATCGCCATTAGAAAGCTTTACCG & TACACTAAACCCTACAAACGTCGA & $\mathrm{C}$ & G & 2 & 217.9 & AC.Combine.Locus_250 \\
\hline 9 & 2 & 126.2 & i26131_2020-HRM & GCTTCTTTGGCCCCATATTCAAG & CATTTGCATAATGTGAGAAAGCGC & $\mathrm{T}$ & $\mathrm{C}$ & 2 & 227.0 & AC.Combine.Locus_1772 \\
\hline 11 & 3 & 20.2 & i39498_201-HRM & AAGAGTTGGGTGTGAAAGGAGATT & CCTGTGTTGAGATTTGGGGATTTC & $\mathrm{T}$ & $\mathrm{C}$ & 3 & 12.7 & AC.Combine.Locus_89589 \\
\hline 12 & 3 & 25.8 & i33531_1155-HRM & CCTTATGCAGATTCACCATGGAAG & CGGATCTCGTTTAACAGTGGAAAG & $\mathrm{T}$ & $\mathrm{C}$ & 3 & 12.7 & AC.Combine.Locus_14239 \\
\hline 13 & 3 & 39.2 & i35038_601-HRM & GACTTGGAGTGCAGTTGAGAC & AATCATCGGGCCTCAATGTTCAA & G & A & 3 & 25.1 & AC.Combine.Locus_14173 \\
\hline 14 & 3 & 100.9 & i26005_1583-HRM & CAGAGATCTCAACTTGTTCCCTGA & ATTGCATACCTCGAATCGCCTTTA & A & G & 3 & 174.0 & AC.Combine.Locus_9082 \\
\hline 15 & 4 & 0 & i29163_2080-HRM & TTCAGTAAACAAAAGATCGGCTGA & AAATCGGCCATCTTATTGTCTCCA & G & A & $4 \mathrm{~B}$ & 0.0 & AC.Combine.Locus_8343 \\
\hline 16 & 4 & 26.2 & i26442_1225-HRM & ACATTCTTCAAAGCGGTAACAACC & CAGTCATATACACCTTTATGCAAGT & A & $\mathrm{G}$ & $4 \mathrm{~A}$ & 28.3 & AC.Combine.Locus_1490 \\
\hline 17 & 4 & 54.3 & i26526_748-HRM & AGGAGGTAATGCACTGATTATTTGT & TGCACAATTGAGAGAAGGTGTTTT & A & G & $4 \mathrm{~B}$ & 52.4 & AC.Combine.Locus_10803 \\
\hline 18 & 4 & 62.0 & i32123_1465-HRM & CACGAATCCATAAGAGTTATCGCA & TGATCAGGGCTAGGAAAGTTTGAT & $\mathrm{T}$ & $\mathrm{C}$ & $4 \mathrm{~B}$ & 52.4 & AC.Combine.Locus_5789 \\
\hline 19 & 5 & 68.6 & i25881_1343-2-HRM & TTCTGACAATTTGACCGGTTGAAG & CGCGGTTACTCAAGGTTTAAGATT & $\mathrm{T}$ & $\mathrm{C}$ & 5 & 59.0 & AC.Combine.Locus_3681 \\
\hline 20 & 5 & 69.1 & i25881_1343-1-HRM & CCATCCTGAACACGATAAACCTTC & GATTAGGAGTTTGGCTTTGCTGTG & $\mathrm{C}$ & $\mathrm{T}$ & 5 & 59.0 & AC.Combine.Locus_3681 \\
\hline 21 & 5 & 85.6 & i29728_1131-HRM & CACAAAGGGGAATCAATAATCGCA & GCCTGCTCTTGGAACTGATAAAAT & $\mathrm{T}$ & $\mathrm{C}$ & 5 & 119.4 & AC.Combine.Locus_2597 \\
\hline 22 & 5 & 112.1 & i30593_868-HRM & TAAAGACCACAACAGACTCGTTCA & TTGGTTAAGGGAGTCTATGTGAGC & $\mathrm{T}$ & $\mathrm{C}$ & 5 & 178.6 & AC.Combine.Locus_70708 \\
\hline 25 & 6 & 54.8 & i30880_1388-HRM & CGTTGGAAGATTATGTTCATCGCA & TTGGCTGCAGTGAAGTAGGTATAG & $\mathrm{C}$ & A & $6 \mathrm{~B}$ & 9.3 & AC.Combine.Locus_8405 \\
\hline 26 & 6 & 73.3 & i35768_1013-HRM & GACATGCCGCAATCCAAGATTAG & CGGTAGATGGTGAAATTTGTGTCA & $\mathrm{T}$ & $\mathrm{C}$ & $6 \mathrm{~B}$ & 30.2 & AC.Combine.Locus_37095 \\
\hline 27 & 6 & 91.1 & i32739_152-HRM & AAACGGCCATCTTGAAGCAATAGA & GCAAAACTTGGTCAGATAGAGAGC & G & A & $6 \mathrm{~B}$ & 41.0 & AC.Combine.Locus_12004 \\
\hline 28 & 6 & 91.7 & i36782_698-HRM & GCATGTTGATAGGAATTCGAATGC & GTGTTGTCTTGTTCTCGTGGTTC & A & $\mathrm{T}$ & $6 \mathrm{~B}$ & 44.3 & AC.Combine.Locus_15991 \\
\hline 29 & 7 & 15.6 & i39918_357-HRM & ATAACCTCTTCTCAATTCGAACTTC & TCCGATCCTCAATGACGACAATAA & $\mathrm{C}$ & G & 7 & 39.1 & AC.Combine.Locus_48105 \\
\hline 30 & 7 & 38.8 & i29101_1894-HRM & CATACCAACCTGCACACTTAAACA & GTACCATAGCGACATCCTATAGCC & A & G & 7 & 92.6 & AC.Combine.Locus_854 \\
\hline 31 & 7 & 43.4 & i28923_2628-HRM & TACTATGGGAATTAGCTACGATGC & AACCGTCTATCCTGGAACCCTA & $\mathrm{C}$ & $\mathrm{T}$ & 7 & 94.8 & AC.Combine.Locus_51 \\
\hline 32 & 8 & 18.2 & i31126_1315-HRM & ACTCTACTTGATGTTCAGTGTGGC & CTTGTCATCATCTTTCCCTAGGCT & $\mathrm{T}$ & $\mathrm{C}$ & 8 & 18.2 & AC.Combine.Locus_2785 \\
\hline 33 & 8 & 22.0 & i30907_420-HRM & TGGCTCTACTGGGGATTTGTTAAA & CACTCGGCAAATATCCCTGGTAG & $\mathrm{C}$ & $\mathrm{T}$ & 8 & 15.4 & AC.Combine.Locus_65044 \\
\hline 34 & 8 & 66.9 & i31261_1350-HRM & GTCCCCTAGAAACAGATCTCCAAC & CGACTGTGACTTTTCGGGAATTTA & A & $\mathrm{C}$ & 8 & 69.4 & AC.Combine.Locus_815 \\
\hline
\end{tabular}

${ }^{\mathrm{z}}$ Map information originated from the results of Duangjit et al. [30]. ${ }^{y}$ Transcript ID information originated from the results of Kim et al. [31]. ${ }^{x}$ Chr. No., chromosome number. 


\subsection{Construction of an Onion Genetic Linkage Map}

An onion genetic linkage map consisting of 319 GBS-based SNPs and 34 HRM markers on eight chromosomes was constructed with a total genetic distance of $881.4 \mathrm{cM}$ (Figure 2, Table 4 and Table S2). The number of markers on each chromosome ranged from 36 to 64 with an average of 44, and the average marker interval was $2.5 \mathrm{cM}$ (Table 4). The shortest and longest chromosomes were 7 and 5 , with genetic distances of $73.9 \mathrm{cM}$ and $142.8 \mathrm{cM}$, respectively (Table 4).

Table 4. Summary of the onion genetic linkage map constructed from an $\mathrm{F}_{2}$ population of SP3B $\times \mathrm{H} 6$.

\begin{tabular}{ccccc}
\hline $\begin{array}{c}\text { Chromosome } \\
\text { No. }\end{array}$ & $\begin{array}{c}\text { Length of Linkage } \\
\text { Maps (cM) }\end{array}$ & $\begin{array}{c}\text { Total Number of } \\
\text { Markers (A+B) }\end{array}$ & $\begin{array}{c}\text { Number of SNPs } \\
\text { Resulting from GBS (A) } \mathbf{z}\end{array}$ & $\begin{array}{c}\text { Number of HRM } \\
\text { Markers (B) } \mathbf{y}\end{array}$ \\
\hline 1 & 122.5 & 36 & 34 & 2 \\
2 & 127.9 & 53 & 46 & 7 \\
3 & 134.1 & 42 & 37 & 5 \\
4 & 94.5 & 38 & 34 & 4 \\
5 & 142.8 & 45 & 39 & 6 \\
6 & 111.3 & 64 & 60 & 3 \\
7 & 73.9 & 38 & 35 & 3 \\
8 & 74.3 & 37 & 34 & 34 \\
Total & 881.4 & 353 & 319 & 4 \\
\hline
\end{tabular}

${ }^{\mathrm{z}}$ GBS, genotyping-by-sequencing. ${ }^{\mathrm{y}} \mathrm{HRM}$, high-resolution melting. 


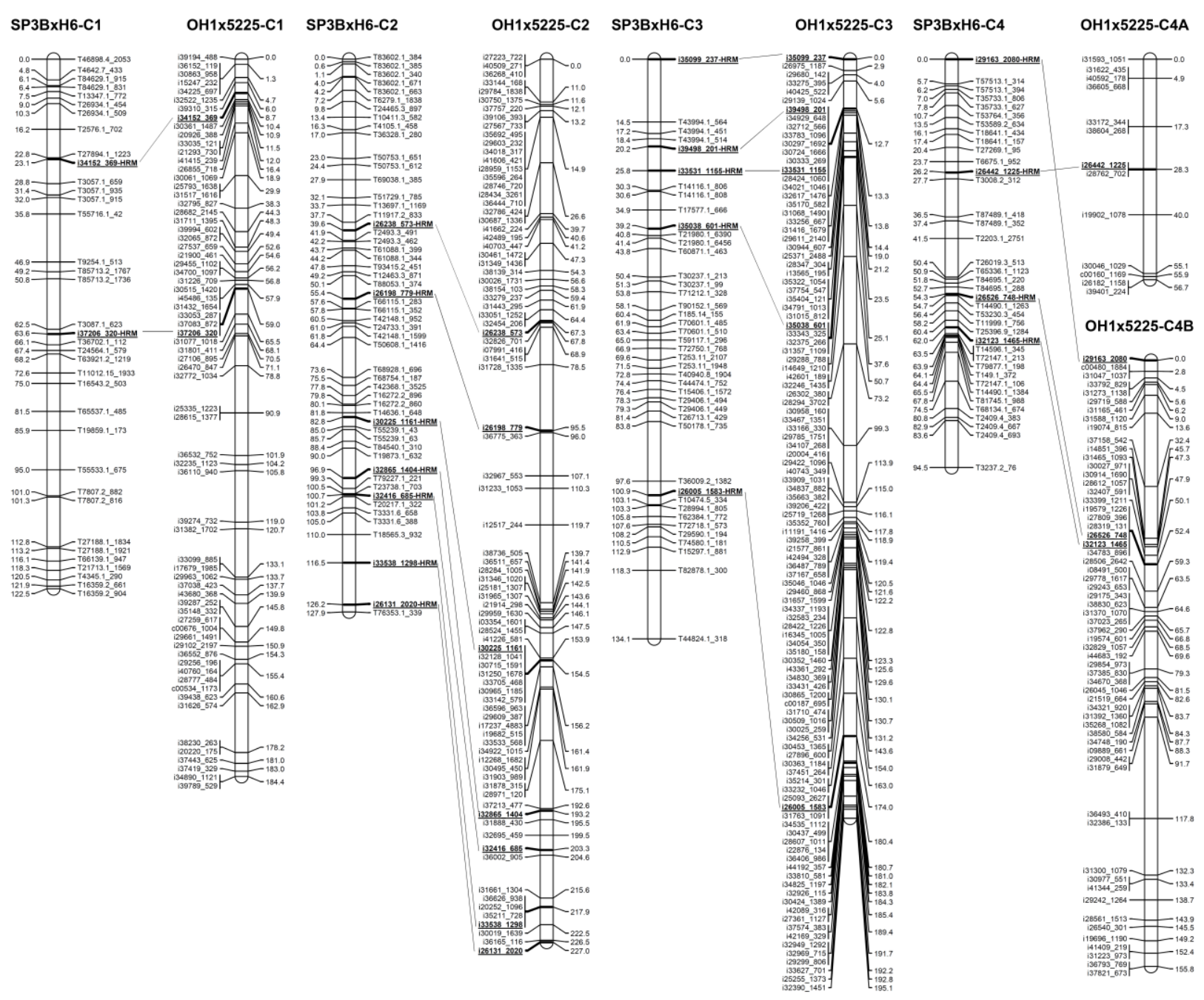

Figure 2. Cont. 

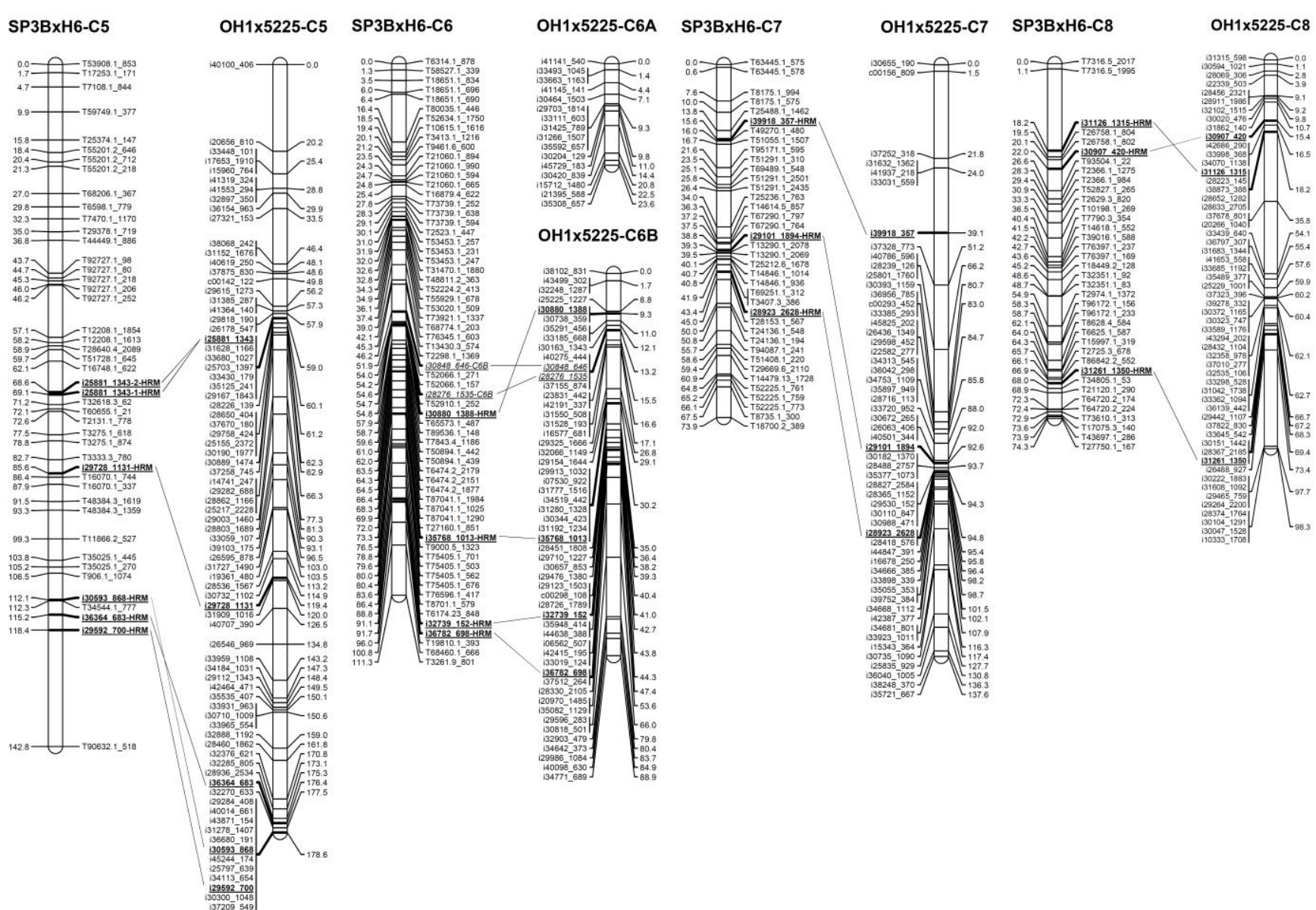

Figure 2. Comparison of two onion genetic linkage maps, the SP3B $\times$ H6 map constructed in this study and the OH1 $\times 5225$ map developed by Duangjit et al. [30]. Bar left or right number, map position (centi Morgan, cM); bar left or right name, marker name; underline, common marker; -HRM in marker name, HRM marker; dotted line, connection between the same transcript-based markers. 


\subsection{Comparison of the SP3B $\times H 6$ and $O H 1 \times 5225$ Onion Genetic Linkage Maps}

The SP3B $\times$ H6 genetic linkage map generated in this study was compared with the previously reported onion reference genetic map for $\mathrm{OH} 1 \times 5225$ to assign each linkage group to the corresponding chromosome (Figure 2). First, through a BLAST search with the mapped transcript sequences, only seven common transcripts were identified; including three (i33531_1155, i35038_601, and i31357_1109) on chromosome 3, one (i37258_745) on chromosome 5, two (i30848_646 and i28276_1535) on chromosome 6B, and one (i31126_1315) on chromosome 8 (Figure 2). Second, a total of 34 HRM markers were developed using SNPs derived from common transcripts (Figure 1 and Table 3). These markers enabled the comparison between $\mathrm{SP} 3 \mathrm{~B} \times \mathrm{H} 6$ and $\mathrm{OH} 1 \times 5225$ (Figure 2).

\subsection{Identification of a Major QTL for Anthocyanin Synthesis of Onion Bulbs}

Only 69 bulbs were harvested from $96 \mathrm{~F}_{2}$ onion plants due to cultivation problems, which were segregated into 51 red bulbs and 18 yellow bulbs (Figure 3), fitting to the segregating ratio of 3:1 (red:yellow; Table 5). This shows that the red bulb color is caused by the expression of a single dominant gene and yellow bulb color results from homozygous recessive alleles of the gene. QTL analysis using these data revealed a major QTL, $q A S 7.1$, for anthocyanin synthesis in the onion (Table 6). This QTL was identified at the $13.8 \mathrm{cM}$ position on chromosome 7 with a logarithm of odds (LOD) score of 9.19 and a phenotypic variance of $87.61 \%$ (Table 6). The segregation of red and yellow bulbs was completely consistent with the genotype of the closest marker (T25488.1_1462) to qAS7.1 (Figure 2 and Table S3). In the marker, the homozygous genotype of SP3B led to yellow bulbs, whereas the homozygous genotype of $\mathrm{H} 6$ or the heterozygous genotype caused red bulbs.

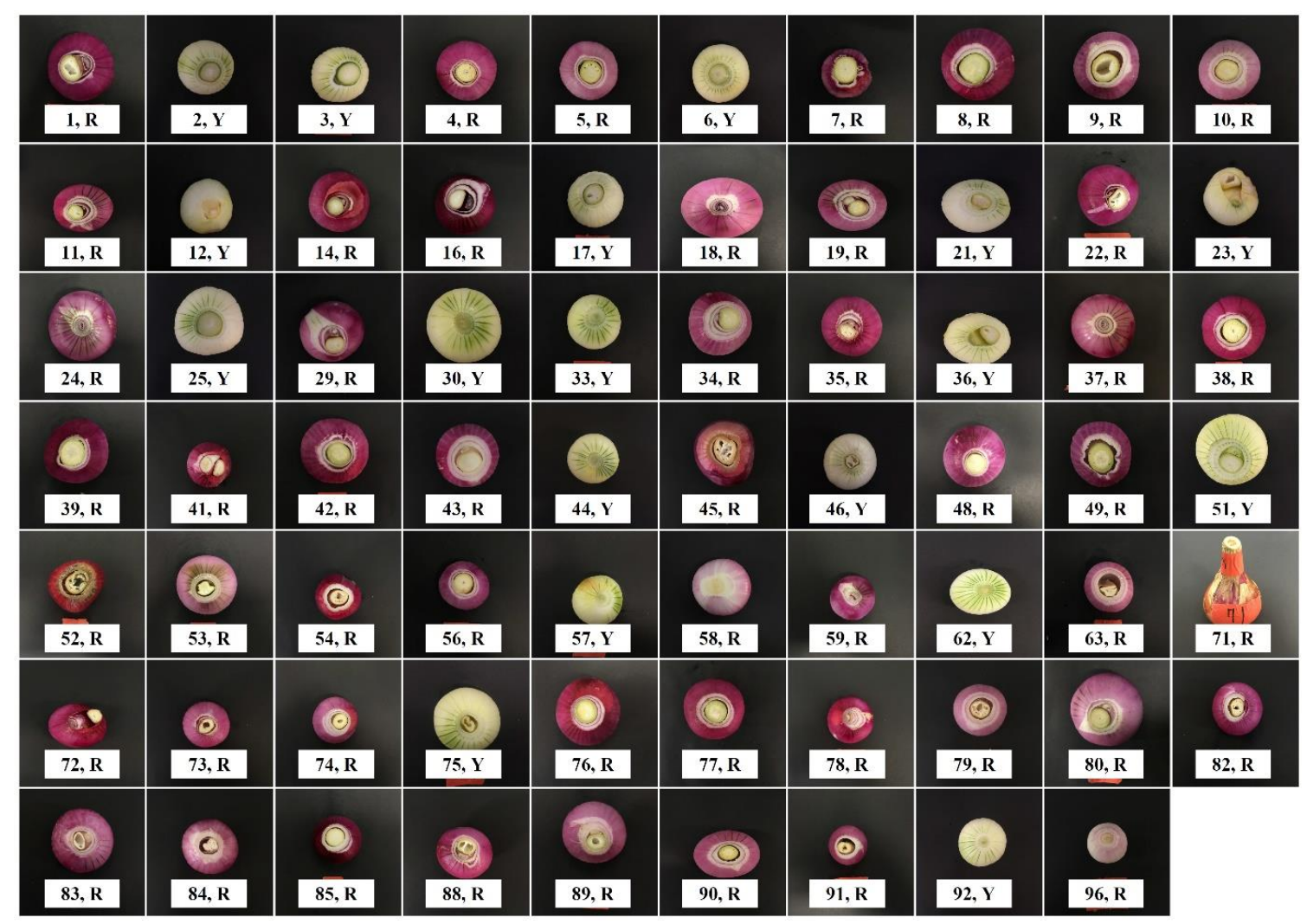

Figure 3. Bulb colors of $69 \mathrm{~F}_{2}$ individuals derived from a cross between Allium cepa 'SP3B' and 'H6'. Numbers, No. of $F_{2}$ individual; $R$, red color; $Y$, yellow color. 
Table 5. Segregation analysis of onion bulb colors in an $\mathrm{F}_{2}$ population of SP3B $\times \mathrm{H} 6$.

\begin{tabular}{|c|c|c|c|c|c|c|c|}
\hline \multirow{2}{*}{ Population } & \multirow{2}{*}{ Generation } & \multicolumn{3}{|c|}{ Number of Onion Plants } & \multirow{2}{*}{$\begin{array}{c}\text { Expected } \\
\text { Ratio }\end{array}$} & \multirow{2}{*}{$X^{2}$ Value } & \multirow{2}{*}{$p$ Value } \\
\hline & & Red Bulb & Yellow Bulb & Total & & & \\
\hline $\mathrm{SP} 3 \mathrm{~B} \times \mathrm{H} 6$ & $\mathrm{~F}_{2}$ & 51 & 18 & 69 & $3: 1$ & 0.0435 & 0.835 \\
\hline
\end{tabular}

Table 6. Summary of significant quantitative trait loci (QTLs) for anthocyanin synthesis and content identified in the $\mathrm{F}_{2}$ onion population of $\mathrm{SP} 3 \mathrm{~B} \times \mathrm{H} 6$.

\begin{tabular}{|c|c|c|c|c|c|c|c|c|c|}
\hline Trait & QTL & Chr. & Marker Interval & $\begin{array}{c}\text { QTL Peak } \\
\text { Position } \\
\text { (cM) }\end{array}$ & $\begin{array}{l}\text { Additive } \\
\text { Effect }\end{array}$ & $\begin{array}{l}\text { Dominance } \\
\text { Effect }\end{array}$ & $\begin{array}{l}R^{2 \mathrm{z}} \\
(\%)\end{array}$ & $\begin{array}{l}\text { LOD }^{y} \\
\text { Value }\end{array}$ & $\begin{array}{c}\text { LOD } \\
\text { Threshold }\end{array}$ \\
\hline $\begin{array}{l}\text { Anthocyanin } \\
\text { synthesis }\end{array}$ & $q A S 7.1$ & 7 & T25488.1_1462-i39918_357-HRM & 13.8 & -0.9573 & 0.2401 & 87.61 & 9.19 & 5.3 \\
\hline Anthocyanin & $q A C 4.1$ & 4 & T57513.1_314-T53764.1_356 & 7.0 & -0.0299 & -0.0513 & 19.43 & 3.26 & 3.0 \\
\hline content & $q A C 4.2$ & 4 & T84695.1_220-i32123_1465-HRM & 62.0 & -0.0399 & -0.0335 & 26.28 & 3.03 & 3.0 \\
\hline
\end{tabular}

\subsection{Identification of Two QTLs for Anthocyanin Content of Onion Bulbs}

Anthocyanin content of 51 red bulbs in the $F_{2}$ population ranged from 0.0098 to $0.5061 \mu \mathrm{g} \times$ $100 \mathrm{mg}^{-1}$ (Figure 4). The average anthocyanin content was $0.0994 \mu \mathrm{g} \times 100 \mathrm{mg}^{-1}$, and the average standard deviation was $0.0133 \mu \mathrm{g} \times 100 \mathrm{mg}^{-1}$. This continuous variation of anthocyanin content indicates that it is quantitatively controlled (Figure 4). Using this data, two significant QTLs, qAC4.1 and $q A C 4.2$, for anthocyanin content of onions were identified by a QTL analysis (Table 6). The QTLs were found at 7 and $62 \mathrm{cM}$ on chromosome 4 with LOD scores of 3.26 and 3.03 and $R^{2}$ values of $19.43 \%$ and $26.28 \%$, respectively (Table 6). The negative additive effects on anthocyanin content were derived from the SP3B genotype and observed in both QTLs (Table 6). A GBS-based marker, T35733.1_806, and an HRM-based marker, i32133_1465-HRM, were the closest markers to qAC4.1 and $q A C 4.2$, respectively (Figure 2 and Table 6). For both markers, the homozygous paternal genotype (B) had the highest total anthocyanin content $\left(0.18 \mu \mathrm{g} \times 100 \mathrm{mg}^{-1}\right.$ in T35733.1_806 and $0.19 \mu \mathrm{g} \times 100 \mathrm{mg}^{-1}$ in T5789-1-C4; Figure 5A,B). The onion lines with both paternal alleles for the markers also showed the highest total anthocyanin content $\left(0.31 \mu \mathrm{g} \times 100 \mathrm{mg}^{-1}\right.$; Figure $\left.5 \mathrm{C}\right)$.

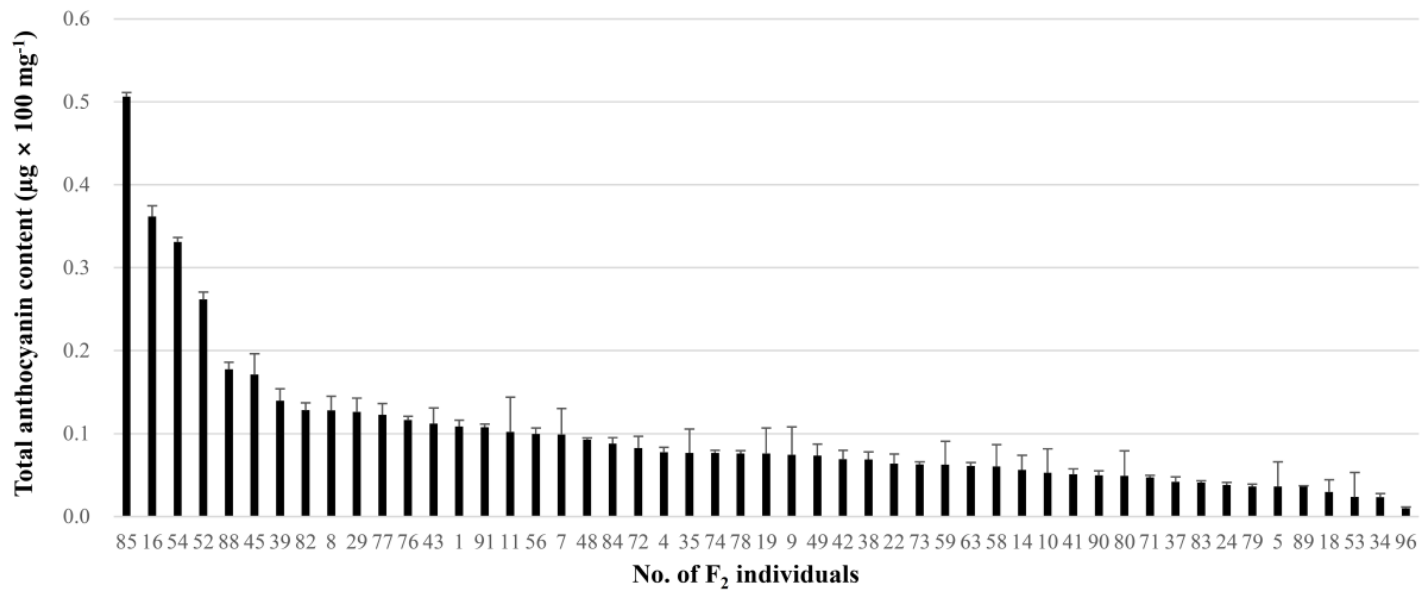

Figure 4. Total anthocyanin content of 51 red bulbs in the $\mathrm{F}_{2}$ population of SP3B $\times \mathrm{H} 6$. 

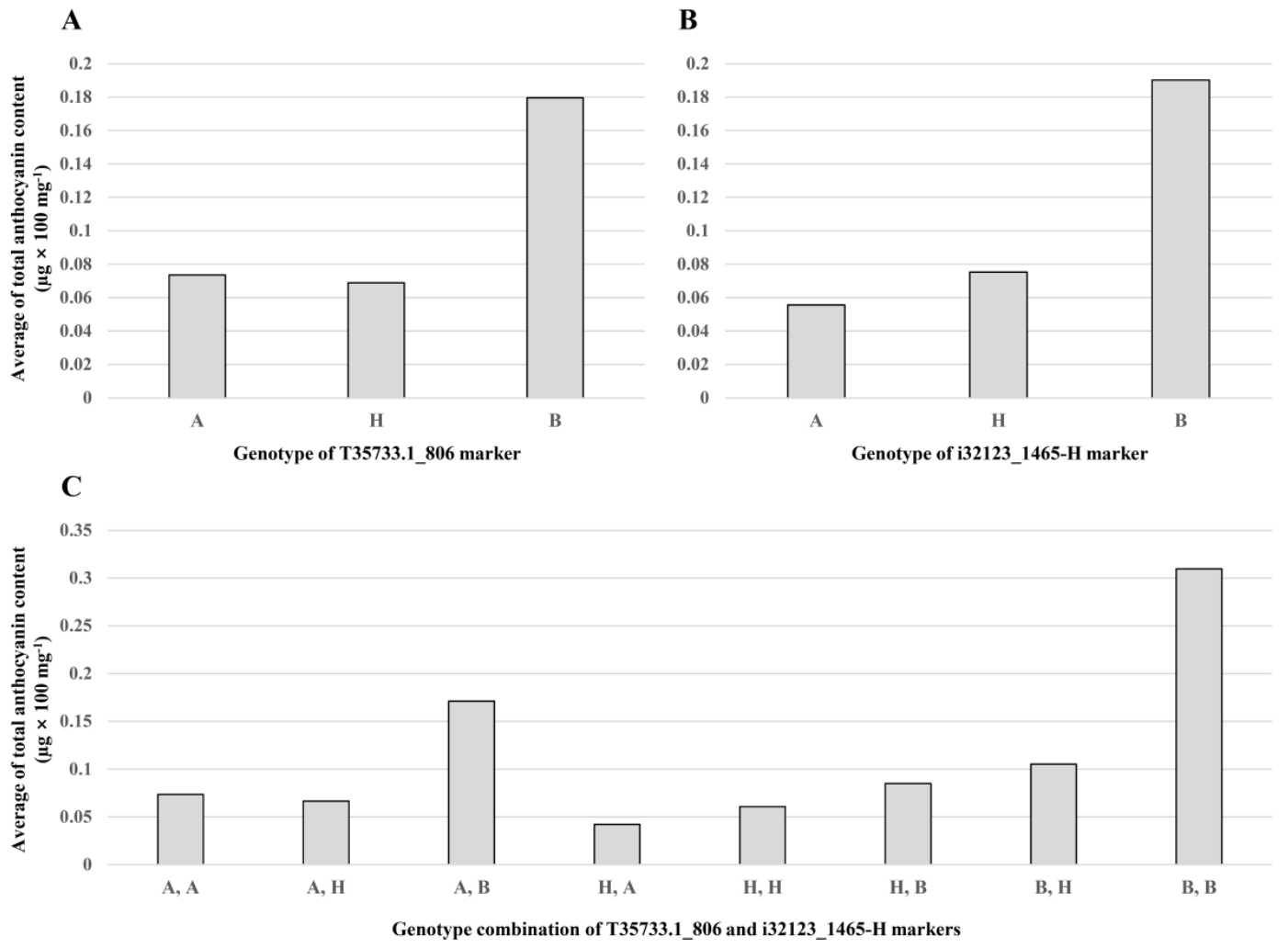

Figure 5. Comparison of the average total anthocyanin content according to genotypes for T35733.1_806 (A) and i32123_1465-H (B) markers and their combinational genotype (C). A, genotype of female parent (SP3B); B, genotype of male parent (H6); H, genotype of heterozygote.

\section{Discussion}

The whole-genome sequence of the bulb onion is not yet made public. Nevertheless, we successfully constructed an onion genetic linkage map using a GBS analysis with the reference of transcriptome sequences (Figure 2). There have been a few reports on the onion genetic map construction using NGS technologies. Baldwin et al. [28] reported 195 molecular markers including 11 Indels, 90 CAPSs, and 104 HRMs derived from NGS data, and Duangjit et al. [30] generated 597 SNP markers from transcriptome sequences using the KASP platform. Jo et al. [34] developed an onion genetic map using reference-free GBS analysis, but only 175 SNPs were mapped. We mapped a total of 319 SNPs in this study, divided into eight linkage groups covering a genetic distance of $881.4 \mathrm{cM}$ (Figure 2 and Table 4). This is the first paper that reports the construction of an onion genetic linkage map using GBS analysis with a reference transcriptome sequence. This method will be useful for onion genetic mapping until the whole genome sequence is released.

The onion genetic linkage map of SP3B $\times \mathrm{H} 6$ was compared with the previously reported genetic map of OH1 $\times 5225$ using common SNP markers (Figure 2) [30]. The 34 developed HRM markers were widely distributed throughout the genome (Figure 2 and Table 3). All the linkage groups of $\mathrm{SP} 3 \mathrm{~B} \times \mathrm{H} 6$ were assigned to the corresponding chromosomes of $\mathrm{OH} 1 \times 5225$ (Figure 2). By doing so, we were able to compare the positions of the QTLs to those detected by Duangjit et al. [36].

Segregation analysis of red and yellow bulb colors revealed the presence of one dominant gene responsible for red color through anthocyanin synthesis (Figure 3 and Table 5). Additionally, QTL analysis for anthocyanin synthesis identified only one major QTL, qAS7.1, on chromosome 7 with a high $R^{2}$ value of $87.61 \%$ (Table 6). In previous studies, El-Shafie and Davis [7] proposed that red bulbs are conditioned by dominant alleles at the $R$ and $L$ loci, and Kim et al. [10,16] suggested that the $R$ locus is DFR and the $L$ locus is ANS. These genes were proven to be complimentarily involved in the control of red and yellow bulb colors using molecular markers [10-12,14,16,18]. In addition, 
hybridization analysis using alien monosomic addition lines suggested that the DFR and ANS genes are located on onion chromosomes 7 and 4, respectively [9]. In this study, qAS7.1-linked marker (T25488.1_1462) cosegregated with bulb colors (red and yellow; Table S3). These results imply that the strongest candidate gene for the QTL $q A S 7.1$ is DFR. However, DFR was not possible to be positioned in this map because a marker for the gene was not developed. We suggest further research on marker development for $D F R$ gene to clarify the assumption.

The distribution of anthocyanin content in $\mathrm{F}_{2}$ onion bulbs suggests the trait is quantitatively controlled (Figure 4). QTL analysis for anthocyanin content of onion bulbs revealed two significant QTLs, $q A C 4.1$ and $q A C 4.2$, on chromosome 4 (Table 6). In a previous study, Duangit et al. [36] identified four QTLs on chromosomes 1, 4, and 8 for anthocyanin concentration and intensity of the red bulb color using segregating haploid progenies of the onion derived from a cross between $\mathrm{OH} 1$ (yellow) and 5225 (red). The QTL on chromosome 4 was closely linked to the three markers c00160_1169, i26182_1158, and i39401_224, which were positioned between 55.9 and 56.7 cM (Figure 2) [30]. It might also correspond to the QTL $q A C 4.1$ since they are located in a similar position (Figure 2). In this study, we additionally found the QTL $q A C 4.2$, which was not detected in the previous study, and no QTLs identified on chromosomes 1 and 8 (Table 6). The $L$ locus was proposed to encode the ANS gene, which is located on onion chromosome 4 [9,16], and Khar et al. [8] reported an additional locus (L2) on chromosome 4 linked to the $L$ locus that also interacts with the $R$ locus to regulate red bulb color. Therefore, the QTLs $q A C 4.1$ and $q A C 4.2$ need to be compared with the $L$ and $L 2$ loci.

The two markers (T35733.1_806 and i32123_1465-H) were closely linked to the QTLs (qAC4.1 and $q A C 4.2)$, respectively (Table 6). The genotypic analysis of the markers showed that the homozygous paternal genotype (B) had the highest anthocyanin content and heterozygous genotype $(\mathrm{H})$ was similar to the homozygous maternal genotype (A; Figure 5A,B). These results suggest that both QTLs are recessive genes. In addition, simultaneous homozygous paternal genotype markers ( $\mathrm{B}$ and $\mathrm{B})$ showed exclusively high anthocyanin content (Figure 5C). This result means that the two QTLs have complementary interaction. Hence, these markers are believed to be very useful for marker-assisted selection for high anthocyanin content in onion breeding.

\section{Materials and Methods}

\subsection{Plant Materials}

An $F_{2}$ segregating population consisting of 96 individuals was used to construct an onion genetic map and identify QTLs for anthocyanin synthesis and content. The population was generated by self-pollination of an $\mathrm{F}_{1}$ hybrid crossed between an inbred onion line with yellow bulb (SP3B) as a maternal line and a short-day type doubled haploid (DH) onion line with red bulb (H6) as a paternal line. The plants were cultivated in the open farm fields of Chonnam National University (Gwangju, South Korea) from October 2017 to June 2018.

\subsection{Phenotyping of Bulb Color}

Phenotypes of anthocyanin-presence and -absence were discriminated by visually observing bulb color; red and yellow bulbs indicate anthocyanin presence and absence, respectively. These phenotypic data were used to identify the position(s) of the gene(s) controlling anthocyanin synthesis.

\subsection{Assessment of Anthocyanin Content}

Total anthocyanin content of the $\mathrm{F}_{2}$ onion bulbs was assessed according to the method described by Shin et al. [37]. Anthocyanin extraction was performed as follows: the twelfth piece of bulb per each sample was crumbled in a mortar with liquid nitrogen. Of the bulb powder $100 \mathrm{mg}$ was placed in a $2.0 \mathrm{~mL}$ microcentrifuge tube with $600 \mu \mathrm{L}$ of extraction buffer (methanol containing $1 \% \mathrm{HCl}$ ), incubated for $6 \mathrm{~h}$ at $4{ }^{\circ} \mathrm{C}$ in dark, and then centrifuged at $4{ }^{\circ} \mathrm{C}$ for $5 \mathrm{~min}$ at $13,000 \mathrm{rpm}$ using a centrifuge (Hanil Scientific Inc., Gimpo, Korea). A $600-\mu \mathrm{L}$ aliquot of the supernatant was transferred to a new $1.5-\mathrm{mL}$ 
microcentrifuge tube, and $200 \mu \mathrm{L}$ of distilled water and $200 \mu \mathrm{L}$ of chloroform:isoamyl alcohol (24:1) were added. The mixture was centrifuged for $5 \mathrm{~min}$ at $13,000 \mathrm{rpm}$ at $4{ }^{\circ} \mathrm{C}$, and $750 \mu \mathrm{L}$ was then transferred to a new 1.5-mL microcentrifuge tube. An aliquot of $300 \mu \mathrm{L}$ was transferred to a new 96-well microplate, and absorbances were measured at $530 \mathrm{~nm}$ and $657 \mathrm{~nm}$ using an Epoch microplate spectrophotometer (BioTek Instruments, Inc., Winooski, VT, USA). The degree of total anthocyanin content was determined by calculating the following function: total anthocyanin content $=\left(A_{530 \mathrm{~nm}}\right)-$ $0.25 \times\left(\mathrm{A}_{657 \mathrm{~nm}}\right)$ [38]. Total anthocyanin content was assessed five times per sample and averaged.

\subsection{DNA Extraction}

Genomic DNA was extracted from young leaves of each $\mathrm{F}_{2}$ individual according to the method described by Lee et al. [39]. The DNA was dissolved in $100 \mu \mathrm{L}$ of distilled water and treated with $0.1 \mu \mathrm{L}$ of $10 \mathrm{mg} \cdot \mathrm{mL}^{-1}$ RNase solution (Bio Basic Canada Inc., Ontario, Canada). The DNA concentration was measured using a BioDrop LITE (BioDrop UK Ltd., Cambridge, UK).

\subsection{Genotyping-by-Sequencing Analysis}

Genomic DNAs from $96 \mathrm{~F}_{2}$ individuals were used to construct the library for GBS analysis. The GBS library was constructed according to the method by Eun et al. [40] with the exception of double digestion with the two restriction enzymes PstI and MspI. The pooled GBS library was sequenced using a HiSeq 2500 (Illumina, Inc., San Diego, CA, USA) using the paired-end read method. The raw sequences were demultiplexed into 96 samples and the demultiplexed sequences were trimmed by removing the barcode, the adapter, and low-quality sequences. The cleaned sequences were aligned to the onion reference gene set consisting of 165,197 assembled contigs (Table 2) [31] using the Burrows-Wheeler alignment (BWA) program version 0.6.1-r104 [41]. Raw SNP detection, consensus sequences extraction, and SNP matrix generation were performed according to the method by Eun et al. [40].

\subsection{High-Resolution Melting Analysis}

HRM analysis was conducted according to the method described by Jeong et al. [42] using a LightCycler ${ }^{\circledR}$ Real-Time PCR (Roche, Basel, Switzerland). The melting curve was analyzed with High-Resolution Melt software version 1.1 (Roche), and the genotypes were classified into three groups: A (SP3B marker type), B (H6 marker type), and H (heterozygous marker type). The newly developed polymorphic HRM markers were added to the SP3B $\times$ H6 map and compared with the $\mathrm{OH} 1 \times 5225$ genetic linkage map [30].

\subsection{Genetic Linkage Mapping}

Genetic linkage maps were constructed using the JoinMap version 4.1 (Kyazma B.V., Wageningen, The Netherlands). Only SNPs fitting with the 1:2:1 ratio of the $\chi^{2}$-test were used (Table S2). A logarithm of odds (LOD) score of 3.0 was regarded as the threshold to determine the significant linkage between markers. Genetic map distances (cM) were calculated by the Kosambi mapping function [43]. The final linkage map was created using the MapChart version 2.1 software [44].

\subsection{Assignment of Linkage Groups to Onion Chromosomes}

Common transcripts were used to assign the linkage groups to onion chromosomes. The transcripts of the reference gene set [31] were compared to those of the standard genetic linkage map OH1 $\times 5225$ [30]. In addition, a total of 248 primer sets for HRM markers were newly designed, which were selected from the SNPs derived from common transcripts between the reference gene set and the previous map OH1×5225.

\subsection{QTL Analysis}

QTL analysis was conducted using windows QTL Cartographer version 2.5 program [45] with the composite interval mapping (CIM) method. The LOD threshold for significance level $(p=0.05)$ was 
estimated with a 1000 times permutation test. QTL analysis was carried out using two phenotypic data: anthocyanin synthesis (AS) and anthocyanin content (AC). Anthocyanin synthesis indicates the presence or absence of anthocyanin, while anthocyanin content refers to high or low amounts of anthocyanin.

\section{Conclusions}

In summary, we performed GBS and HRM analyses on $96 \mathrm{~F}_{2}$ onion plants and constructed a genetic linkage map with 319 SNPs and 34 HRM markers, consisting of eight linkage groups and covering $881.4 \mathrm{cM}$ with an average marker interval of $2.5 \mathrm{cM}$. Through QTL analysis, we identified a major QTL, qAS7.1, for anthocyanin synthesis and two significant QTLs, $q A C 4.1$ and $q A C 4.2$, for anthocyanin content in the onion. In conclusion, the map information of the transcripts and markers will contribute to complete the onion whole-genome sequencing, and the QTL information for anthocyanin synthesis and content will be useful for molecular marker development for marker-assisted selection (MAS). This will help to facilitate the breeding of bulb onions with higher anthocyanin content.

Supplementary Materials: The following are available online at http://www.mdpi.com/2223-7747/9/5/616/s1, Table S1: The SNP matrix generated by GBS analysis, Table S2: Statistics for GBS-based SNP and HRM markers mapped in this study, Table S3: Cosegregation of the SNP marker (T25488.1_1462) with bulb color in an $F_{2}$ population of $\mathrm{SP} 3 \mathrm{~B} \times \mathrm{H} 6$.

Author Contributions: J.L. conceived the project and wrote the manuscript; Y.C. performed the analysis and made the figures and tables; S.K. provided onion materials and cultivated the onions. All authors have read and agreed to the published version of the manuscript.

Funding: This work was supported by the Korea Institute of Planning and Evaluation for Technology in Food, Agriculture, and Forestry (IPET) through the Golden Seed Project (grant number: 213007-05-4-WTB11), funded by the Ministry of Agriculture, Food and Rural Affairs (MAFRA), Ministry of Oceans and Fisheries (MOF), Rural Development Administration (RDA), and Korea Forest Services (KFS), Republic of Korea.

Conflicts of Interest: The authors declare no conflict of interest.

\section{Abbreviations}

$\begin{array}{ll}\text { AC } & \text { anthocyanin content } \\ \text { AFLP } & \text { amplified fragment length polymorphism } \\ \text { ANS } & \text { anthocyanidin synthase } \\ \text { AS } & \text { anthocyanin synthesis } \\ \text { CAPS } & \text { cleaved amplified polymorphic sequence } \\ \text { CIM } & \text { composite interval mapping } \\ \text { cM } & \text { centi Morgan } \\ \text { ddRAD-seq } & \text { double digest restriction site-associated DNA sequencing } \\ \text { DFR } & \text { dihydroflavonol 4-reductase } \\ \text { EST } & \text { expressed sequence tag } \\ \text { GBS } & \text { genotyping-by-sequencing } \\ \text { HRM } & \text { high-resolution melting } \\ \text { KASP } & \text { kompetitive allele specific PCR } \\ \text { LOD } & \text { logarithm of odds } \\ \text { MAS } & \text { marker-assisted selection } \\ \text { NGS } & \text { next-generation sequencing } \\ \text { QTL } & \text { quantitative trait loci } \\ \text { RAPD } & \text { random amplified polymorphic DNA } \\ \text { RFLP } & \text { restriction fragment length polymorphism } \\ \text { SNP } & \text { single-nucleotide polymorphism } \\ \text { SSCP } & \text { single-strand conformation polymorphism } \\ \text { SSR } & \text { simple sequence repeat }\end{array}$




\section{References}

1. Khosa, J.S.; McCallum, J.; Dhatt, A.S.; Macknight, R.C. Enhancing onion breeding using molecular tools. Plant Breed. 2016, 135, 9-20. [CrossRef]

2. Griffiths, G.; Trueman, L.; Crowther, T.; Thomas, B.; Smith, B. Onions-A global benefit to health. Phytother. Res. 2002, 16, 603-615. [CrossRef] [PubMed]

3. Gu, K.D.; Wang, C.K.; Hu, D.G.; Hao, Y.J. How do anthocyanins paint our horticultural products? Sci. Hort. 2019, 249, 257-262. [CrossRef]

4. Terahara, N.; Yamaguchi, M.; Honda, T. Malonylated anthocyanins from bulbs of red onion, Allium cepa L. Biosci. Biotech. Biochem. 1994, 58, 1324-1325. [CrossRef]

5. Donner, H.; Gao, L.; Mazza, G. Separation and characterization of simple and malonylated anthocyanins in red onions, Allium cepa L. Food Res. Int. 1997, 30, 637-643. [CrossRef]

6. Clarke, A.E.; Jones, H.A.; Little, T.M. Inheritance of bulb color in the onion. Genetics 1944, 29, 569-575.

7. El-Shafie, M.W.; Davis, G.N. Inheritance of bulb color in the onion (Allium cepa L.). Hilgardia 1967, 38, 607-622. [CrossRef]

8. Khar, A.; Jakse, J.; Havey, M.J. Segregations for onion-bulb colors reveal that red is controlled by at least three loci. J. Am. Soc. Hortic. Sci. 2008, 133, 42-47. [CrossRef]

9. Masuzaki, S.; Shigyo, M.; Yamauchi, N. Complete assignment of structural genes involved in flavonoid biosynthesis influencing bulb color to individual chromosomes of the shallot (Allium cepa L.). Genes Genet. Syst. 2006, 81, 255-263. [CrossRef]

10. Kim, S.; Binzel, M.L.; Park, S.; Yoo, K.S.; Pike, L.M. Inactivation of DFR (Dihydroflavonol 4-reductase) gene transcription results in blockage of anthocyanin production in yellow onions (Allium cepa). Mol. Breed. 2004, 14, 253-263. [CrossRef]

11. Kim, S.; Yoo, K.S.; Pike, L.M. Development of a PCR-based marker utilizing a deletion mutation in the dihydroflavonol 4-reductase (DFR) gene responsible for the lack of anthocyanin production in yellow onions (Allium cepa). Theor. Appl. Genet. 2005, 110, 588-595. [CrossRef] [PubMed]

12. Kim, S.; Baek, D.; Cho, D.Y.; Lee, E.T.; Yoon, M.K. Identification of two novel inactive DFR- $A$ alleles responsible for failure to produce anthocyanin and development of a simple PCR-based molecular marker for bulb color selection in onion (Allium cepa L.). Theor. Appl. Genet. 2009, 118, 1391-1399. [CrossRef] [PubMed]

13. Song, S.; Kim, C.W.; Moon, J.S.; Kim, S. At least nine independent natural mutations of the $D F R-A$ gene are responsible for appearance of yellow onions (Allium cepa L.) from red progenitors. Mol. Breed. 2014, 33, 173-186. [CrossRef]

14. Kim, B.; Cho, Y.; Kim, S. Identification of a novel DFR-A mutant allele determining the bulb color difference between red and yellow onions (Allium cepa L.). Plant Breed. Biotechnol. 2017, 5, 45-53. [CrossRef]

15. Kim, S.; Binzel, M.L.; Yoo, K.S.; Park, S.; Pike, L.M. Pink $(P)$, a new locus responsible for a pink trait in onions (Allium cepa) resulting from natural mutations of anthocyanidin synthase. Mol. Genet. Genom. 2004, 272, 18-27. [CrossRef] [PubMed]

16. Kim, S.; Jones, R.; Yoo, K.S.; Pike, L.M. The L locus, one of complementary genes required for anthocyanin production in onions (Allium cepa), encodes anthocyanidin synthase. Theor. Appl. Genet. 2005, 111, 120-127. [CrossRef]

17. Kim, S.; Yoo, K.S.; Pike, L.M. Development of a codominant PCR-based marker for allelic selection of the pink trait in onions (Allium cepa), based on the insertion mutation in the promoter of the anthocyanidin synthase gene. Theor. Appl. Genet. 2005, 110, 573-578. [CrossRef]

18. Kim, E.Y.; Kim, C.W.; Kim, S. Identification of two novel mutant ANS alleles responsible for inactivation of anthocyanidin synthase and failure of anthocyanin production in onion (Allium cepa L.). Euphytica 2016, 212, 427-437. [CrossRef]

19. Chen, F.; Dong, W.; Zhang, J.; Guo, X.; Chen, J.; Wang, Z.; Lin, Z.; Tang, H.; Zhang, L. The sequenced angiosperm genomes and genome databases. Front. Plant Sci. 2018, 9, 418. [CrossRef]

20. King, J.J.; Bradeen, J.M.; Bark, O.; McCallum, J.A.; Havey, M.J. A low-density genetic map of onion reveals a role for tandem duplication in the evolution of an extremely large diploid genome. Theor. Appl. Genet. 1998, 96, 52-62. [CrossRef] 
21. Van Heusden, A.W.; van Ooijen, J.W.; Vrielink-van Ginkel, R.; Verbeek, W.H.J.; Wietsma, W.A.; Kik, C. A genetic map of an interspecific cross in Allium based on amplified fragment length polymorphism (AFLP ${ }^{\mathrm{TM}}$ ) markers. Theor. Appl. Genet. 2000, 100, 118-126. [CrossRef]

22. Van Heusden, A.W.; Shigyo, M.; Tashiro, Y.; Vrielink-van Ginkel, R.; Kik, C. AFLP linkage group assignment to the chromosomes of Allium cepa L. via monosomic addition lines. Theor. Appl. Genet. 2000, 100, 480-486. [CrossRef]

23. McCallum, J.; Leite, D.; Pither-Joyce, M.; Havey, M.J. Expressed sequence markers for genetic analysis of bulb onion (Allium cepa L.). Theor. Appl. Genet. 2001, 103, 979-991. [CrossRef]

24. Martin, W.J.; McCallum, J.; Shigyo, M.; Jakse, J.; Kuhl, J.C.; Yamane, N.; Pither-Joyce, M.; Gokce, A.F.; Sink, K.C.; Town, C.D.; et al. Genetic mapping of expressed sequences in onion and in silico comparisons with rice show scant colinearity. Mol. Genet. Genom. 2005, 274, 197-204. [CrossRef] [PubMed]

25. Jakše, J.; Martin, W.; McCallum, J.; Havey, M.J. Single nucleotide polymorphisms, indels and simple sequence repeats for onion (Allium cepa L.) cultivar identification. J. Am. Soc. Hortic. Sci. 2005, 130, 912-917. [CrossRef]

26. McCallum, J.; Thomson, S.; Pitcher-Joyce, M.; Kenel, F.; Clarke, A.; Havey, M.J. Genetic diversity analysis and single nucleotide polymorphism marker development in cultivated bulb onion based on expressed sequence tag-simple sequence repeats markers. J. Am. Soc. Hortic. Sci. 2008, 113, 810-818. [CrossRef]

27. Varshney, R.K.; Nayak, S.N.; May, G.D.; Jackson, S.A. Next-generation sequencing technologies and their implications for crop genetics and breeding. Trends Biotechnol. 2009, 27, 522-530. [CrossRef]

28. Baldwin, S.; Revanna, R.; Thomson, S.; Pither-Joyce, M.; Wright, K.; Crowhurst, R.; Fiers, M.; Chen, L.; Macknight, R.; McCallum, J. A toolkit for bulk PCR-based marker design from next-generation sequence data: Application for development of a framework linkage map in bulb onion (Allium cepa L.). BMC Genom. 2012, 13, 637. [CrossRef]

29. Baldwin, S.; Pither-Joyce, M.; Wright, K.; Chen, L.; McCallum, J. Development of robust genomic simple sequence repeat markers for estimation of genetic diversity within and among bulb onion (Allium cepa L.) populations. Mol. Breed. 2012, 30, 1401-1411. [CrossRef]

30. Duangiit, J.; Bohanec, B.; Chan, A.P.; Town, C.D.; Havey, M.J. Transcriptome sequencing to produce SNP-based genetic maps of onion. Theor. Appl. Genet. 2013, 126, 2093-2101. [CrossRef]

31. Kim, S.; Kim, M.S.; Kim, Y.M.; Yeom, S.I.; Cheong, K.; Kim, K.T.; Jeon, J.; Kim, S.; Kim, D.S.; Sohn, S.H.; et al. Integrative structural annotation of de novo RNA-Seq provides an accurate reference gene set of the enormous genome of the onion (Allium cepa L.). DNA Res. 2015, 22, 19-27. [CrossRef] [PubMed]

32. Sohn, S.H.; Ahn, Y.K.; Lee, T.H.; Lee, J.E.; Jeong, M.H.; Seo, C.H.; Chandra, R.; Kwon, Y.S.; Kim, C.W.; Kim, D.S.; et al. Construction of a draft reference transcripts of onion (Allium cepa) using long-read sequencing. Plant Biotechnol. Rep. 2016, 10, 383-390. [CrossRef]

33. Scholten, O.E.; van Kaauwen, M.P.W.; Shahin, A.; Hendrickx, P.M.; Keizer, L.C.P.; Burger, K.; van Heusden, A.W.; van der Linden, C.G.; Vosman, B. SNP-markers in Allium species to facilitate introgression breeding in onion. BMC Plant Biol. 2016, 16, 187. [CrossRef] [PubMed]

34. Jo, J.; Purushotham, P.M.; Han, K.; Lee, H.R.; Nah, G.; Kang, B.C. Development of a genetic map for onion (Allium cepa L.) using reference-free genotyping-by-sequencing and SNP assays. Front. Plant Sci. 2017, 8, 1606. [CrossRef] [PubMed]

35. Lee, J.H.; Natarajan, S.; Biswas, M.K.; Shirasawa, K.; Isobe, S.; Kim, H.T.; Park, J.I.; Seong, C.N.; Nou, I.S. SNP discovery of Korean short day onion inbred lines using double digest restriction site-associated DNA sequencing. PLoS ONE 2018, 13, e0201229. [CrossRef]

36. Duangit, J.; Welsh, K.; Wise, M.L.; Bohanec, B.; Havey, M.J. Genetic analyses of anthocyanin concentrations and intensity of red bulb color among segregating haploid progenies of onion. Mol. Breed. 2014, 34, 75-85. [CrossRef]

37. Shin, J.; Park, E.; Choi, G. PIF3 regulates anthocyanin biosynthesis in an HY5-dependent manner with both factors directly binding anthocyanin biosynthetic gene promoters in Arabidopsis. Plant J. 2007, 49, 981-994. [CrossRef]

38. Mancinelli, A.L.; Schwartz, O.M. The photoregulation of anthocyanin synthesis IX. The photosensitivity of the response in dark and light-grown tomato seedlings. Plant Cell Physiol. 1984, 25, 93-105.

39. Lee, Y.R.; Kim, J.; Lee, S.Y.; Lee, J. Diallelic SNP marker development and genetic linkage map construction in octoploid strawberry (Fragaria $\times$ ananassa) through next-generation resequencing and high-resolution melting analysis. Hortic. Environ. Biotechnol. 2020, 61, 371-383. [CrossRef] 
40. Eun, M.H.; Han, J.H.; Yoon, J.B.; Lee, J. QTL mapping of resistance to the Cucumber mosaic virus P1 strain in pepper using a genotyping-by-sequencing analysis. Hortic. Environ. Biotechnol. 2016, 57, 589-597. [CrossRef]

41. Li, H.; Durbin, R. Fast and accurate short read alignment with Burrows-Wheeler transform. Bioinformatics 2009, 25, 1754-1760. [CrossRef] [PubMed]

42. Jeong, K.; Choi, D.; Lee, J. Fine mapping of the genic male-sterile $m s_{1}$ gene in Capsicum annuum L. Theor. Appl. Genet. 2018, 131, 183-191. [CrossRef] [PubMed]

43. Kosambi, D.D. The estimation of map distance from recombination value. Ann. Eugen. 1944, 12, $172-175$. [CrossRef]

44. Voorrips, R.E. MapChart: Software for the graphical presentation of linkage maps and QTLs. J. Hered. 2002, 93, 77-78. [CrossRef]

45. Wang, S.; Basten, C.J.; Zeng, Z.B. Windows QTL Cartographer 2.5; Department of Statistics, North Carolina State University: Raleigh, NC, USA, 2007.

(C) 2020 by the authors. Licensee MDPI, Basel, Switzerland. This article is an open access article distributed under the terms and conditions of the Creative Commons Attribution (CC BY) license (http://creativecommons.org/licenses/by/4.0/). 